\title{
MODEL IMPLEMENTASI STRATEGI SEBAGAI DETERMINAN KINERJA BISNIS KETIKA PANDEMI COVID-19
}

\author{
Suaibatul Aslamiyah \\ Prodi Manajemen, Fakultas Ekonomi dan Bisnis \\ Universitas Muhammadiyah Gresik \\ suaibatul.aslamiyah@umg.ac.id
}

\begin{abstract}
SMES, as the largest economic driving sector in Indonesia, are experiencing a very serious impact from thei COVID-19 pandemic. This is indicated by 56 percent reporting a decline in sales, 22 percent reporting problems in the financing aspect, 15 percent reporting problems with distribution of goodsiand 4 percent reporting difficulties in getting raw raw materials. Azky Collection as oneiof the MSMEs in Gresik, is the one who has been iaffected and has carried out previous strategic planning since the pandemic. Using qualitative descriptive research methods, this study aims to describe the strategy implementation model used in Azky Collection SMEs, and the supporting and inhibiting factors that influence the achievement of the best performance. There are 2 research informants, 2 business owners from 2 generations. The analysis technique uses Yin analysis technique (2011) which is divided into 5 (five) phases, (1) compiling,i (2) disassembling,i(3) reassemblingi(and arraying), (4) interpreting,iand (5) concluding.i The results showed that the implementation of the strategy carried out by UKM Azky Collection had a good impact on sales reports as a determinant of performance. This canibeiseen from despite the iCOVID-19 pandemic conditions, Azky Collection was able to survive with the chosen strategy, namely product development and was able to increase sales to 3600 products in 2021. The supporting factors for implementing the strategy consisted of (1) external, consisting of (a) the number of consumers there are a lot of headscarves, (b) a growing and developing market and the needs of hijab users that still exist, (2) internal, consisting of (a) a solid team, (b) experience, (c) affordable prices, (d) quality. While the inhibiting factors for strategy implementation are (1) Promotion, (2) Structure, (3) Financial management.
\end{abstract}

Keywords: smes, strategy implementation, covid-19, performance.

$\triangle$ Corresponding author:

Email Address : suaibatul.aslamiyah@umg.ac.id (Gresik, Jawa Timur)

Received 3 Januari 2022, Accepted 7 Pebruari 2022, Published 23 Pebruari 2022

\section{PENDAHULUAN}

Perekonomian nasional, banyak didukung oleh kontribusi UMKM, dengan kinerja yang terus berkembang. Menurut data dari Kementerian Koperasi dan UMKM, pada tahun 2013 UMKM mampu menyumbangkan 5.440 triliun rupiah (atas dasar harga berlaku) terhadap PDB Nasional, menyerap tenaga kerja 114,14 juta orang, menarik 1.655,2 triliun rupiah investasi, dengan total ljumlah UMKM sebanyak 57,8 juta unit. Gambar 1 menyajikan kontribusi UMKM dalam perekonomian nasional tahun 2013-2014.

Kemampuan perusahaan menghadapi persaingan menjadi penentu tercapai tidaknya kinerja. Jika perusahaan lebih kuat dari pesaingnya, maka mereka dapat memenangkan

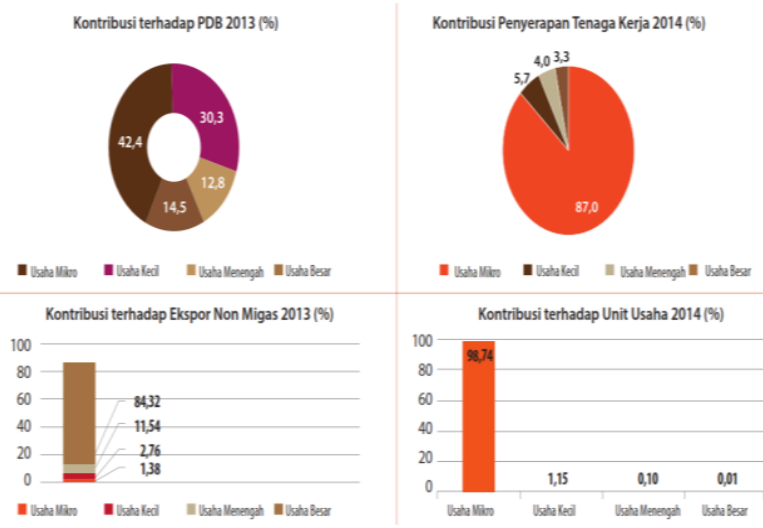

Sumber: Asian Development Bank (2014)

Gambar 1. Kontribusi UMKM dalam Perekonomian Nasional 
persaingan dan mencapai kinerja yang diinginkan. Hal ini sesuai dengan pernyataan dari Hill dan Jones (2011) yang menyatakan bahwa tujuan utama strategi adalah untuk mencapai suatu keunggulan bersaing. Hal ini menunjukkan bahwa tanpa strategi, maka suatu bisnis akan mengalami hambatan dalam mencapai tujuannya.

Kemungkinan berhasilnya strategi dan tujuan perusahaan sangat dipengaruhi oleh lingkungan eksternal dan internal. Lingkungan eksternal merupakan lingkungan bisnis yang melingkupi operasi perusahaan, sehingga bisa memunculkan peluang dan ancaman. Sedangkan lingkungan internal, mencakup manajemen fungsional dan budaya perusahaan Suwarsono (2014). Kondisi lingkungan eksternal, antara lain dapat dilihat pada sektor ekonomi. Kajian yang dilakukan oleh kementerian keuangan menunjukkan bahwa pandemi COVID-19 memberikan implikasi negative bagi perekonomian domestic, seperti penurunan konsumsi dan daya beli masyarakat, penurunan kinerja perusahaan, ancaman pada sektor perbankan dan keuangan serta eksistensi UMKM (Santoso, 2020).

Pada sektor UMKM, menurut Kemenkop UKMI ada sekitar 37.000 UMKM yang memberikan laporan bahwa mereka terdampak sangat serius dengan adanya pendemi, hal ini ditandai dengan 56\% melaporkan terjadi penurunan penjualan, $22 \%$ melaporkan permasalahan pada aspek pembiayaan, $15 \%$ melaporkan pada masalah distribusi barang dan $4 \%$ melaporkan kesulitan mendapatkan bahan baku mentah (Rahman, 2020). Kondisi terbaru, Bank Indonesia menyebutkan sebanyak $87,5 \%$ UMKM terdampak pandemiICOVID-19, dan sekitar 93,2\% diantaranya terdampak negatif di sisi penjualan (Sari, 2021). Pandemic COVID-19 dan berbagai macam dampak yang ditimbulkan diatas hingga saat ini, membutuhkan strategi yang tepat terutama bagi para pelaku UMKM agar bisa terus mempertahankan usahanya.

Mengatasi permasalahan terkait pandemic COVID-19 yang menimpa UMKM, strategi yang diambil harus mampu beradaptasi dengan sangat cepat, baik level organisasi/perusahaan, korporat, unit bisnis atau level operasional. Salah satu contoh UMKM yang menggunakan strategi dalam bisnisnya adalah Azky Collection. Azky Collection dipilih karena sudah melaksanaan formulasi strategi sebelumnya, sehingga sesuai dengan langkahlangkah penerapan manajemen strategi. Temuan riset Aslamiyah, S (2020) menyimpulkan bahwa Azky Collection dalam formulasi strategi yang digunakan pada saat pandemic adalah pengembangan produk. Namun, dalam konsep manajemen strategi, proses terpenting adalah lebih menekankan pada tahap implementasi yang banyak tantangannya, sehingga penelitian ini merupakan kelanjutan dari proses sebelumnya pada UKM Azky Collection. Adapun tujuan Penelitian ini adalah untuk mengetahui dan menganalisis model implementasi strategi dan faktor-faktor yang mendukung serta menghambat implementasi strategi di Azky Collection yang menghasilkan kinerja terbaik dari perusahaan saat pandemi COVID-19.

\section{TINJAUAN PUSTAKA}

\section{Penelitian Terdahulu}

Beberapa peneliti telah banyak melakukan kajian empiris berkaitan dengan Implementasi strategi bisnis. Namun saat ini belum ada pembuktian atau pembahasan mengenai implementasi strategi bisnis terhadap kinerja ketika pandemic COVID-19. Maka untuk mendukung penelitian ini, terdapat kajian-kajian empiris atau penelitian terdahulu berkaitan dengan hal tersebut, antara lain sebagai berikut.

Pella, Darmin., et.al. (2013) dengan judul penelitian "Model Implementasi Strategi Sebagai Determinan Kinerja Perusahaan" menemukan bahwa Terdapat pengaruh siginifikan 7 faktor tahapan implementasi strategi dan 9 faktor kapabilitas pendukung implementasi strategi terhadap kesuksesan implementasi strategi dan kinerja. Selanjutnya, Anggraini, Felicia., Sukaatmadja, I Putu Gede (2015), dengan judul penelitian "Implementasi Strategi Kemitraan, Diferensiasi dan Layanan Untuk Meningkatkan Kinerja Industri Kuliner di Kota Denpasar", menemukan bahwa penerapan strategi kemitraan, diferensiasi dan layanan pada industri kuliner dapat meningkatkan kinerja perusahaan. Sedangkan Ingga, Ibrahim (2016) dengan judul penelitian "Implementasi Manajemen Strategi", menemukan bahwa lingkungan eksternal memiliki pengaruh dominan dalam 
implementasi strategi dibandingkan lingkungan internal, nilai pelanggan dan keunggulan bersaing. Berdasarkan hal tersebut, maka penelitian berkaitan dengan kinerja UMKM pada saat pandemi COVID-19 dan telah melakukan implementasi strategi belum pernah diteliti, sehingga menjadi celah penelitian ini.

\section{Kajian Teoritis}

\section{Manajemen Strategi}

Menurut Pearch II dan Robinson (2016: 3) menyatakan bahwa manajemen strategi merupakan suatu perangkat keputusan dan tindakan yang menghasilkan formulasi dan implementasi rencana yang dirancang untuk mencapai suatu tujuan perusahaan. Sedangkan menurut Hunger dan Whelen (2013), manajemen strategi adalah serangkaian keputusani dani tindakan manajerial yang menentukan kinerja perusahaan dalam jangka panjang. Dengan demikian, dapat disimpulkan bahwa manajemen strategi adalah seperangkat tindakan komprehensif yang terpadu untuk menghasilkan perumusan dan pelaksanaan rencana agar tercapai kinerja terbaik.

Implementasi mempunyai peran terpenting dalam manajemen strategi suatu perusahaan, karena implementasi berkaitan dengan berhasil tidaknya suatu perusahaan mencapai tujuan perusahaan. Menurut Pearch II dan Robinson (2016) Implementasi strategi dapat dilakukan melalui 4 tahapan berikut:

1. Penciptaan tujuan jangka pendek yang jelas dan rencana tindakan.

2. Pengembangan taktik fungsional khusus yang dapati menciptakan keunggulan bersaing.

3. Pemberdayaan personel operasional melalui kebijakan untuk mengarahkan keputusan.

4. Implementasi sistem reward yang efektif.

\section{Kinerja Bisnis}

Kinerja merupakan hasil dari bisnis yang telah dilakukan wirausahawan pada masa lalu, dan digunakan sebagai alat pengukur prestasi kerja dengan menggunakan metode penilaian tertentu (Taman, 2011). Selanjutnya, Jauch dan Glueck (2012) menyatakan bahwa kinerja (performance) perusahaan dapat dilihat dari tingkat penjualan, tingkat keuntungan, pengembalian modal, tingkat turn over dan pangsa pasar yang diraihnya. Sehingga kinerja merujuk pada tingkat pencapaian dalam periode waktu tertentu, yakni kinerja merupakan hal yang sangat menentukan dalam perkembangan dan kelangsungan hidup perusahaan.

\section{METODOLOGI PENELITIAN}

Pendekatan penelitian yang digunakan adalah deskriptif kualitatif. Lokasi penelitian di UKM Azky Collection yang berada di Desa Melirang Wetan, Kecamatan Bungah, Kabupaten Gresik. Menggunakan teknik judgement sampling. Informan penelitian yang digunakan sebanyak 2 orang, yakni owner bisnis dari 2 generasi, karena dari sudut pandang peneliti memilih, owner adalah yang paling menguasi berkaitan dengan strategi bisnis. Sumber data yang digunakan adalah data primer yang berupa hasil wawancara peneliti dengan informan dan data-data sekunder yang berupa artikel dari penelitian terdahulu serta data pendukung lain.

Teknik pengumpulan data yang digunakan dalam penelitian ini adalah observasi partisipasi dengan langkah eksploratif, yaitu salah satu teknik pengumpulan data kualitatif yang dianjurkan untuk mendapatkan data-data deskriptif (Gunawan, 2017). Teknik analisis menggunakan teknis analisis Yin (2011) yang terbagi dalam 5 (lima) fase, yaitu (1) compiling, (2) disassembling, (3) reassembling (and arraying), (4) interpreting, dan (5) concluding. Sedangkan untuk mengukur keabsahan data peneliti menggunakan teknik triangulasi sebagai uji konsistensi terhadap sumber data (Sugiyono, 2019).

\section{HASIL DAN PEMBAHASAN}

Azky Collection adalah UKM jilbab yang ada di desa Melirang Wetan, Kecamatan Bungah Kabupaten Gresik. Azky Collection memiliki karyawan sebanyak 12 orang, yang hingga sekarang mampu terus mengembangkan usahanya hingga sepuluh tahun, mulai tahun 2010 dan sekarang dikelola oleh generasi kedua. UKM ini memiliki beberapa produk jilbab, dengan basis pelanggan yang jelas melalui toko grosir di pabean, Surabaya. Pemilik UKM ini juga mempertahankan hubungan dekat dengan pelanggannya, yang dapat memungkinkan mendeteksi pergeseran dalam keinginan dan kebutuhan pelanggan.

\section{Model Implementasi Strategi}

Sebelum implementasi, ada kegiatan yang telah 
dilakukan oleh Azky Collection, yakni formulasi strategi. Pada kegiatan formulasi strategi yang telah dilakukan oleh Azky Collection sebelumnya, diketahui bahwa strategi yang terbaik untuk bisa meningkatkan daya saing ketika pandemic adalah pengembangan produk Aslamiyah, S. (2021), sedangkan pada kegiatan implementasi strategi, terdapat beberapa hal yang dilakukan oleh Azky Collection, antara lain terlihat dari upaya pencapaian visi perusahaan. Mengacu pada hasil wawancara dengan owner, diketahui bahwa visi Azky Collection adalah "Menjadi produsen kebutuhan muslimah yang modern dan diterima semua kalangan"

Upaya pencapaian visi perusahaan memerlukan pentahapan atau periodisasi pelaksanaan aktivitas. Periodisasi tersebut dapat dibagi menjadi tujuan jangka panjang dan tujuan jangka pendek. Tujuan jangka panjang diwujudkan dalam perencanaan jangka panjang berupa program, sedangkan tujuan jangka pendek diwujudkan dalam perencanaan jangka pendek berupa anggaran.

Tujuan jangka pendek membantu implementasi strategi dalam tiga cara: pertama, tujuan jangka pendek mengoperasionalisasi tujuan jangka panjang. Kedua, mendiskusikan dan menyetujui tujuan jangka pendek, membantu mengungkap masalah dan konflik yang potensial dalam suatu organisasi yang biasanya membutuhkan koordinasi untuk menghindari konsekuensi yang tidak semestinya. Ketiga, tujuan jangka pendek membantu implementasi untuk mengetahui hasil dari rencana tindakan atau aktivitas fungsional, yang dapat digunakan untuk melakukan umpan balik, koreksi dan evaluasi yang lebih relevan dan dapat diterima (Pearce II dan Robinson JR., 2016).

Tujuan jangka pendek dicapai dengan rencana tindakan melalui tiga cara, yakni: pertama, rencana tindakan mengenali taktik fungsional dan aktivitas yang akan dilaksanakan dalam minggu depan, bulan, atau kuartal sebagai bagian dari usaha bisnis untuk membangun keunggulan bersaing. Kedua, elemen dari suatu rencana tindakan adalah bingkai waktu yang jelas untuk penyelesaian, ketika usaha akan dimulai dan ketika hasilnya akan dicapai. Ketiga, elemen rencana tindakan mengandung pengenalan siapa yang bertanggungjawab untuk setiap tindakan dalam perencanaan (Pearch II dan Robinson J, 2016).
Pada Azky Collection, rencana tindakan disesuaikan dengan permintaan dari pelanggan, melalui desain atau model baru yang dibuat. Desain baru yang di tawarkan biasanya tiap bulan, dan tetap memantau perkembangan permintaannya tiap kuartal. Selain desain yang sudah launching di pasaran, Azky Collection akan membuat rencana produk maupun desain jilbab baru, yang mungkin sedang diminati oleh banyak kalangan, hal ini biasanya dengan melihat model-model hijab merek terkenal yang di buat atau dipakai artis Indonesia, sehingga menghasilkan model jilbab yang up-to-date. Salah satu contoh, Azky Collection yang awalnya produsen jilbab, melalui proses perencanaan strategi, saat ini juga membuat produk berupa cadar dan masker yang banyak dibutuhkan dan dicari saat pandemic COVID19 ini.

Pearch II dan Robinson Jr. (2016) mengemukakan langkah-langkah pengendalian, agar sistem pengendalian operasional menjadi efektif harus melakukan empat tahapan umum pada semua tindakan pengendalian, yakni:

1. Menetapkan standar kinerja.

2. Mengukur kinerja yang sesungguhnya.

3. Mengidentifikasi penyimpangan dari standar yang telah ditetapkan.

4. Berinisiatif melakukan tindakan koreksi.

Terdapat tiga tipe sistem pengendalian operasional, yaitu: anggaran, skedul, dan faktor kunci keberhasilan. Pada saat penyusunan standar atau perencanaan, manajemen membutuhkan informasi akuntansi, antara lain informasi biaya, baik yang berkaitan dengan masa lalu maupun masa yang akan datang. Pengukuran kinerja yang sesungguhnya dapat dikatakan sebagai penyusunan laporan mengenai hasil pelaksanaan anggaran. Informasi yang dihasilkan dalam system informasi akuntan ialah berupa laporan penjualan, biaya produksi, biaya operasional, neraca dan laporan laba-rugi. Laporan tersebut dibandingkan dengan standar, apakah standar tercapai atau tidak. Hasil perbandingan ini mendadi dasar tindakan perbaikan selanjutnya (Ingga, Ibrahim. 2016).

Pengendalian kinerja Azky Collection dapat dilihat pada jumlah penjualan. Saat ini, penjualan produk Azky Collection masih secara offline atau langsung kerjasama dengan tokotoko jilbab yang punya stand di pasar pabean Surabaya. Ada 20 toko yang menjadi mitra kerjasama. Dengan alokasi anggaran produksi 
sebenar 5 juta tiap berproduksi per minggu, Azky Collection bisa menjual sekitar rata-rata 10 kodi produk jilbab. Jika dilihat secara penjualan perbulan, maka kinerja $A z k y$ Collection dengan strategi pengembangan produknya bisa dilihat pada Gambar 2 berikut.

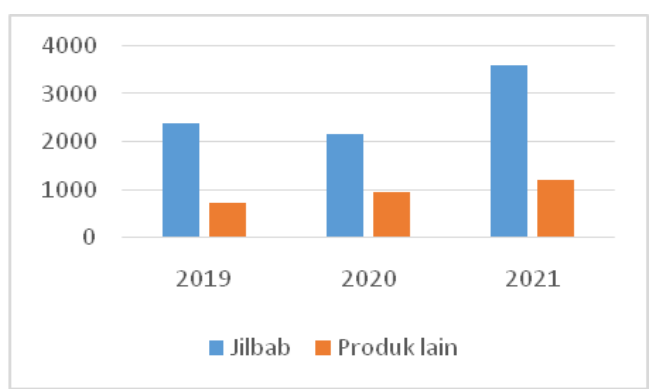

Sumber: Data diolah (2022)

\section{Gambar 2. Kinerja Penjualan Azky Collection}

Pada Gambar 2 di atas, dapat diketahui bahwa hasil dari adanya formulasi strategi yang dilakukan sebelumnya telah memberikan efek positif berupa peningkatan jumlah penjualan. Hal ini terlihat dari jumlah penjualan yang meningkat, yakni awalnya tahun 2019 sejumlah 2400 pcs, kemudian 2020 sejumlah 2160 pcs, dan pada 2021 meningkat menjadi 3600 pcs.

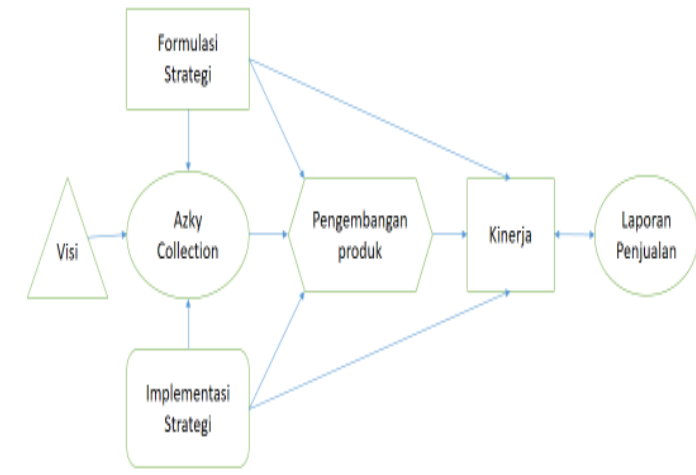

Sumber: Data diolah, (2022)

\section{Gambar 3. Model Implementasi Strategi Azky Collection}

Selain ini, kinerja laporan penjualan yang baik juga terlihat pada produk lain yang dikembangkan menyesuaikan kondisi pandemic yakni membuat produk masker atau cadar yang sebelumnya tidak diproduksi namun ada produk lain berupa dalaman jilbab (iket). Hal tersebut mampu menjadikan Azky Collection bangkit lagi dari penurunan penjualan sebelumnya yang terdampak pandemic COVID-19 pada awal kemunculannya. Berikut merupakan hasil analisis model implementasi strategi sebagai determinan kinerja bisnis ketika pandemi COVID-19 pada Azky Collection (Gambar 3).

\section{Faktor Pendukung Implementasi Strategi \\ Kesuksesan implementasi strategi} didefinisikan sebagai keberhasilan melaksanakan proses untuk melaksanakan kebijakan, program, dan tindakan tertentu yang telah diputuskan manajemen pada seluruh organisasi (Harrington and Kendall, 2006). Berdasarkan hasil analisis dan data dari penelitian sebelumnya, maka diketahui faktorfaktor yang mendukung dari segi internal dan eksternal pada implementasi strategi, yakni (1) eksternal, terdiri dari (a) jumlah konsumen jilbab yang banyak, hal ini karena mayoritas pemeluk agama islam di jawa timur utama di Gresik adalah muslimah yang berkerudung, sehingga meskipun pandemic jilbab tetap dibutuhkan dan diminati, (b) market yang tumbuh dan berkembang serta kebutuhan pengguna jilbab yang masih terus ada, hal ini dapat dilihat dari perkembangan mode jilbab yang terus berkembang, misalnya: model kerut atau jilbab syar'i.

Faktor pendukung berikutnya adalah (2) internal, terdiri dari (a) tim yang solid, dapat dilihat dari karyawan yang bertahan hingga lebih dari 5 tahun, (b) pengalaman, dapat dilihat dari cara mempertahankan loyalitas pelanggan dan jumlah penjualan yang stabil, (c) harga terjangkau, produk dari Azky Collection relative terjangakau dan membidik konsumen menengah ke bawah, (d) kualitas, meskipun harga bersaing Azky Collection tetap mempertahankan kualitas dan melakukan pengecekan tiap produk sebelum di jual. Selain itu, hal yang menjadikan kunci usaha ini masih eksis adalah kepemimpinan yang baik dari 2 generasi usaha jilbab Azky Collection yang cenderung mengayomi dan terbuka.

\section{Faktor Penghambat Implementasi Strategi} Implementasi strategi di UKM Azky Collection selain didukung oleh faktor pendukung yang menjadi keberhasilan strategi, juga terdapat faktor penghambat, yaitu (1) Promosi, penjualan Azky Collection yang masih offline atau door to door menjadikan hambatan dalam penjualan, yakni hanya mengandalkan pelanggan lama, (2) Struktur, yakni belum ada struktur organisasi yang jelas, cendenrung one man show atau owner merangkap beberapa 
kegiatan manajemen, (3) Manajemen keuangan, yakni belum ada pencatatan keuangan yang sistematis.

\section{SIMPULAN}

Implementasi strategi yang dilakukan UKM Azky Collection memberikan dampak yang baik terhadap laporan penjualan sebagai determinan kinerja. Hal ini terlihat dari meskipun kondisi pandemi COVID-19, Azky Collection bisa survive dengani strategi yang dipilih yaitu pengembangan produk dan mampu menjadikan penjualan naik menjadi 3600 pcs pada 2021. Faktor pendukung implementasi strategi terdiri (1) eksternal, terdiri dari (a) jumlah konsumen jilbab yang banyak, (b) market yang tumbuh dan berkembang serta kebutuhan pengguna jilbab yang masih terus ada, (2) internal, terdiri dari (a) tim yang solid, (b) pengalaman, (c) harga terjangkau, (d) kualitas. Sedangkan faktor penghambat implementasi strategi adalah (1) Promosi, (2) Struktur, (3) Manajemen keuangan.

\section{DAFTAR PUSTAKA}

Asiani Developmenti Bank.i2014. Asia SME Finance Monitor 2014. Mandaluyong City: ADB.

Aslamiyah, Suaibatul. 2021. Formulasi Strategi UKM Jilbab Azky Collection untuk Meningkatkan Daya Saing Di Masa Pandemi Covid-19. JURNAL MANAJERIAL, [S.1.], v. 8, n. 01, p. 102117, jan. 2021. ISSN 2621-5055. Online, melalui

http://journal.umg.ac.id/index.php/manaj erial/article/view/2121 Diakses tanggal 1 Oktober 2021.

Aslamiyah, Suaibatul. 2021. The Role of Strategy Toward Business Performance in Hijab Small Business. Advances in Social Science, Education and Humanities Research, volume 585, Proceeding of the 1st UMGESHIC internasional Seminar on Health, Social Science and Humanities (UMGESHIC1SHSSH 2020). Atlantis Press SARL. Online, melalui https://www.atlantispress.com/proceedings/umgeshic-ishssh20/125961943 diakses pada tanggal 03 Oktober 2021.

Gunawan, I. 2017. Metode Penelitian Kualitatif. Jakarta: Bumi Aksara.
Harrington. R.J., Kendall, K.W. 2006. Strategy Implementation Success: The Moderating Effects ofSize and Environmental Complexity and the Mediating Effects of Involvement. Journal of Hospitality \& Tourism Research. 30: 207

Ingga, Ibrahin. 2016. Implementasi Manajemen Strategic. Ed.1, Cet.1. Yogyakarta: Deepublish.

Pearce, John A., Robinson, Richard B. 2016. Manajemen Strategi: Formulasi, Implementasi, dan Pengendalian, Edisi 12. Jakarta: Salemba Empat.

Rahman, Riska. 2020. 37.000 SMEs hit by Covid-19 crisis as government prepares aid. Online, melalui https://www.the jakartapost.com/news/2020/04/16/37000sme-hit-by-covid-19-crisis-asgovernment-prepares-aid.html. pada tangal 8 agustus 2021.

Sari, yunita resmi. 2021. Survei BI : 87,5 Persen UMKM Indonesia Terdampak Pandemi Covid-19. Online, melalui https://ekonomi.bisnis.com/read/2021031 9/9/1370022/ pada tanggal 7 Oktober 2021

Santoso, Yusuf Imam. 2020. Menghitung dampak Covid-19 terhadap dunia usaha hingga UMKM. Online, melalui https://nasional.kontan.co.id/news/mengh itung-dampak-covid-19-terhadap-duniausaha-hingga-umkm?page $=$ all. $\quad$ Pada tanggal 7 september 2021.

Sugiyono. 2009. Metode Penelitian Kuantitatif, Kualitatif dan R\&D. Bandung: Alfabeta.

Yin, Robert K. 2011. Qualitative Research From Start fo Finish. New York: The Guilford Press. 